\title{
Rocuronium Versus Cis-Atracurium in Rapid Sequence Induction of Morbidly Obese Patients; Prospective Randomized Clinical Trial
}

\author{
EMAN M. TAHER, M.Sc.; SALAH-ELDIN I. ELSHERIF, M.D.; NAGAT S. ELSHMAA, M.D. and \\ SAMEH A. AHMED, M.D. \\ The Department of Anesthesia and Surgical Intensive Care, Faculty of Medicine, Tanta University, Egypt
}

\begin{abstract}
Background: The use of larger doses of neuromuscular blockers may shorten the onset of intubation.

Aim of Study: This study aimed to evaluate the use of triple the (ED 95) of rocuronium or cis-atracurium on the timing and the score of intubation in morbidly obese patients.

Patients and Methods: Sixty adult morbid obese patients were included in this study and allocated randomly according to the muscle relaxant used for induction of anesthesia into either ROC group; in which $0.9 \mathrm{mg} / \mathrm{kg}$ of rocuronium was used or CIS group; in which $0.15 \mathrm{mg} / \mathrm{kg}$ of cis-atracurium was used. The onset and the duration of relaxation, the time of intubation, the intubation score, and the incidence of complication were measured. In addition, the changes in the hemodynamic parameters were recorded.

Results: In comparison to cis-atracurium, the use of triple (ED95) of rocuronium in rapid sequence induction of anesthesia significantly shortened the onset of relaxation from $96.00 \pm 13.29$ to $84.00 \pm 18.50 \mathrm{sec}$ ( $p=0.005$, CI $3.675 ; 20.325$ ), and the time of intubation from $104.55 \pm 17.91$ to $89.14 \pm 20.43$ $\sec (p=0.002$, CI $6.00 ; 24.82)$. However, the duration of relaxation was significantly prolonged from $58.76 \pm 9.27$ to $69.86 \pm 8.38 \mathrm{~min}(p=0.003$, CI $2.533 ; 11.667)$. Moreover, the intubation score was comparable between the two groups $(p=0.994)$
\end{abstract}

Conclusion: The use of triple the (ED 95) of rocuronium as compared to cis-atracurium in rapid sequence induction of anesthesia of morbidly obese patients significantly shortened the onset of relaxation and the time of inubation with an insignificant effect on the intubation score.

Clinical trial registration:Pan African Clinical Trial Registry (PACTR201703002147145) (www.pactr.org).

Key Words: Rocuronium - Cis-atracurium - Onset of intubation - Intubation score.

\section{Introduction}

OBESITY is a global health problem. Its prevalence had been increased markedly over the past

Correspondence to: Dr. Eman M. Taher,

E-Mail: (emantaher6669@gmail.com). decades. Obesity is associated with several hazards with anesthesia, one of those hazards is the increased risk of pulmonary aspiration the requires an effective rapid sequence induction of anesthesia for quick airway securing after the loss of consciousness $[\mathbf{1 , 2}]$.

The rapid onset of action and the relatively short duration of action of suxamethonium render it the muscle relaxant of choice in the intubation process in the obese patients. However, certain side effects and complications limit its use as muscle pains, bradycardia, hyperkalemia, and raised intra-ocular pressure. It may also act as a trigger for malignant hyperthermia [3]. Several clinical studies were conducted to evaluate the ability to perform rapid sequence induction of anesthesia with the aid of non-depolarizing neuromuscular blockers in order to avoid the suxamethonium side effects [4].

The non-depolarizing aminosteroidal neuromuscular blocker, rocuronium bromide, can create an intubating condition similar to that created by the suxamethonium. It has an onset of action of 60 seconds and a duration of action of about 37-72 minutes with the use of standard dose [5,6]. Also, the benzylisoquinoline non-depolarizing neuromuscular blocker agent, cisatracurium besylate, can create a good intubating condition within two minutes if used in a dose of $0.1 \mathrm{mg} / \mathrm{kg}$ with the advantage of an intermediate duration of action. There are many clinical trials that purposed to speed up the onset of action of cisatracurium by administration of larger doses or the use of priming dose $[\mathbf{7 , 8 ]}$.

The use of the triple the $95 \%$ mean effective dose (ED 95) of rocuronium or cisatracurium may fasten and facilitate the intubation process in morbid 
obese patients. We purposed to compare the effect of the use of rocuronium or cisatracurium (Triple ED95) on the timing of the intubation (Primary outcome) and the intubation score (Secondary outcome).

\section{Patients and Methods}

At Tanta University Hospitals, this clinical prospective randomized study was carried out immediately after it obtained an ethical committee approval (The Institutional Ethical committee of the Tanta Faculty of medicine at January 2017 with its number 31323/01/17) and registered on the Pan African clinical trial registry at 26 th March 2017 (Its identification number of clinical registration was PACTR201703002147145). The study lasted for a period of 12 months (from April 2017 to March 2018). An informed written consent was obtained from all the participants.

Patients who were included in this clinical trial were American Society of Anesthesiology (ASA) class II-III, aged 20-40 years, and their body mass index ranged from $40-50 \mathrm{~kg} / \mathrm{m}^{2}$. The exclusion criteria of the study consisted of refusal of patients to participate, major cardiac, renal, hepatic, or musculoskeletal disorders, pregnancy, known or suspected allergy to the used medications, BMI more than $50 \mathrm{~kg} / \mathrm{m}^{2}$, or patients who offered awake intubation. Every patient had received an adequate explanation of the aim, technique, advantage, disadvantages, and potential risk of the study. Secret codes and private files were used to ensure the privacy of the patients. The collected data were used only in this study.

All the patients were assessed preoperatively in the anesthesia clinic through history taking, clinical general and local examination, and requesting routine laboratory investigations including $\mathrm{CBC}$, liver function tests, kidney function tests, and coagulation studies. Then, patients were counseled and reassured with obtaining informed consent from the participants.

According to the neuromuscular blocking agent used for the induction of anesthesia, patients were randomly distributed by the aid of computer generated software into two groups:

Rocuronium group: Where induction of anesthesia was conducted by rocuronium $0.9 \mathrm{mg} / \mathrm{kg}$ (lean body weight).

Cisatracurium group: where $0.15 \mathrm{mg} / \mathrm{kg}$ (lean body weight) of cisatracurium were used for induction of anesthesia.
An anesthetist who was not participating in the research helped in the preparation of the muscle relaxants in uniform syringes and introduced them in closed sealed envelopes.

Once the patient was admitted to the operating theatre without premedication, intravenous access was obtained through the insertion of 20 gauge peripheral venous cannula with starting fluid preload of lactated ringer solution $10 \mathrm{ml} / \mathrm{kg}$. Then, the patient was attached to a monitor of ECG tracing 5 leads, non-invasive blood pressure, pulse oximeter, end-tidal $\mathrm{CO} 2$ using (sidestream capnography), esophageal temperature, and peripheral nerve stimulation (tactile train of four count).

Acceleromyography was used for monitoring of the neuromuscular function ((TOF-watch-SX, MSD BV, Oss, The Netherlands). The neuromuscular monitoring was established through ulnar nerve stimulation by the use of two electrodes, one was placed at the lateral side of the tendon of flexor carpi ulnaris $1 \mathrm{~cm}$ proximal to the wrist skin crease and the second was placed $3-4 \mathrm{~cm}$ proximal to the wrist with the placement of the sensor at the tip of the thumb. This arrangement causes stimulation of the flexor carpi ulnaris muscle that flexes and adducts the wrist and also augments thumb abduction. The neuromuscular monitoring was calibrated after induction of anesthesia and before injection of muscle relaxant.

After 5 minutes of pre-oxygenation through well-fitted face mask using $80 \%$ oxygen, anesthesia was induced with intravenous fentanyl $1.5 \mathrm{gg} / \mathrm{kg}$ (lean body weight) followed by intravenous propofol $1.5 \mathrm{mg} / \mathrm{kg}$ (lean body weight). Supramaximal stimulation delivered in train-of-four (TOF) every 15 seconds was carried out till reaching stable twitch height which was considered as a control. Then, the intubating dose of the muscle relaxant was injected. Rocuronium bromide $0.9 \mathrm{mg} / \mathrm{kg}$ IV in ROC group and cisatracurium $0.15 \mathrm{mg} / \mathrm{kg}$ IV in CIS group. A trial of video- laryngosc opy was performed when there was $95 \%$ suppression of twitch height after the muscle relaxant injection, then the intubating conditions was evaluated using four point scale [excellent, good, poor, or inadequate] [9]. Tracheal intubation was performed when the intubation score was excellent or good. However, the endotracheal intubation was postponed if the intubation score was poor or inadequate with repetition of the video-laryngoscopy trial after 30 seconds until the score became excellent or good. The time interval from injection of NMB till 95\% suppression of TOF was considered as the onset 
of relaxation, while, the time elapsed between the injection of NMB and successful intubation was considered as the timing of intubation.

Anesthesia was maintained using isoflurane inhalation to reach a MAC of 1.2 through fresh gas flow composed of Oxygen: Air 1:1 and incremental doses of non-depolarizing muscle relaxant (Rocuronium in a dose of $0.3 \mathrm{mg} / \mathrm{kg}$ in group ROC or Cisatracurium in a dose of $0.03 \mathrm{mg} / \mathrm{kg}$ in group CIS) when TOF decreased to $30 \%$. Additional incremental doses of fentanyl $0.5 \mathrm{ug} / \mathrm{kg}$ (lean body weight) were used in case of increased the mean arterial pressure or the heart rate by more than $30 \%$ of the baseline values. Mechanical ventilation was established by volume controlled mode to maintain end-tidal $\mathrm{CO} 2$ between $35-40 \mathrm{mmHg}$. Protective lung strategy was used through the use of a tidal volume of $6 \mathrm{ml} / \mathrm{kg}$ (lean body weight) and stepwise PEEP for maintaining of adequate ventilation of the basal alveoli. Esophageal temperature was kept between $36-370 \mathrm{c}$ through surface warming.

The isoflurane was switched off at the end of the surgery with antagonizing the muscle relaxants by neostigmine $(0.05 \mathrm{mg} / \mathrm{kg})$ and atropine $(0.01 \mathrm{mg} /$ $\mathrm{kg}$ ) given by slow intravenous injection when TOF reached $70 \%$. The patients were extubated awake and transferred to the recovery room for monitoring and follow-up till discharge.

An anesthetist who was not participating in this research work and was blinded to the groups helped in the measurement and recording of the onset of relaxation in seconds, the timing of intubation in seconds (Primary outcome), the intubation score (Secondary outcome), and any adverse events as skin reaction, bronchospasm or $\mathrm{O}_{2}$ desaturation. Moreover, the duration of relaxation that represented the elapsed time from reaching $95 \%$ suppression of TOF twitches till regaining of $25 \%$ of the height of the twitches was measured.

Also, the hemodynamic variables that included mean arterial blood pressure (MAP) $\mathrm{mmHg}$, and heart rate (HR) bpm were measured before induction of anesthesia (T0), after induction and before injection of NMB (T1), after injection of NMB and before endotracheal intubation (T2), and just after intubation (T3).

Statistical analysis: Sample size calculation based upon previous study [10] revealed that at least 29 patients in each group were required for detection of a significant difference in the timing of intubation of 30 seconds at $\alpha$ value of 0.05 and $95 \%$ power of the study. The statistical analysis of this research was carried out using The SPSS 17 (SPSS Inc., 215 Chicago, IL, USA). Categorical data were expressed as number and percentage after analysis using chi-square test while parametric data were analyzed by unpaired $t$-test and expressed as mean $\pm \mathrm{SD}$. $p$-value $<0.05$ denoted significant change.

\section{Results}

Seventy-six obese patients were assessed if they were eligible for this clinical study or not, 16 of them were excluded (12 patients did not meet the inclusion criteria of the study and 4 patients refused the participation), the other 60 patients were randomly allocated into either ROC group (30 patients) or CIS group (30 patients). Fig. (1).

The mean values of the basic criteria of the studied patients that included age, sex, body mass index, the type of the surgery, and the duration of the surgery were comparable among the two groups ( $p=0.634,0.791,0.899,0.826,0.966$ respectively). The incidence of skin reaction, bronchospasm, or oxygen desaturation was indifferent between the two groups ( $p=0.554,0.554$ and 1.0 respectively). Table (1).

The onset of relaxation was significantly prolonged in the cisatracurium group than the rocuronium group ( $p=0.005,95 \%$ CI: $3.675 ; 20.325)$. Moreover, the timing of intubation was statistically significantly shortened in the rocuronium group as compared to cisatracurium group ( $p=0.002,95 \%$ CI: $6.00 ; 24.82)$. In addition, there was statistical significant prolongation in the duration of relaxation in the rocuronium group than the cisatracurium group ( $p=0.003,95 \%$ CI: $2.533 ; 11.667$ ) Table (2). However, the intubation score was comparable between the two groups $(p=0.994)$. The intubation score in ROC group was excellent in 15 patients $(50 \%)$, good in 10 patients $(33.3 \%)$, poor in 3 patients $(10 \%)$ and inadequate in two patients (6.7\%) and in CIS group the intubation score was excellent in 14 patients (46.7\%), good in 11 patients (36.7\%), poor in 3 patients $(10 \%)$ and inadequate in two patients (6.7\%). Table (3).

The mean values of the heart rate decreased significantly from the baseline values in the two groups after induction of anesthesia, after injection of muscle relaxants, and after intubation ( $p<$ 0.0001 ). Comparison between the two groups revealed an insignificant statistical difference in the heart rate at all time intervals ( $p>0.05)$. Fig. (2).

Moreover, the mean values of the mean arterial pressure in the two groups showed statistically 
significant decrease following induction of anesthesia, injection of the muscle relaxants, and endotracheal intubation as compared to the baseline values $(p<0.0001)$ with an insignificant difference between the two groups throughout all time intervals $(p>0.05)$. Fig. (3).

Table (1): Patients and surgical characteristics and incidence of complication in the studied groups.

\begin{tabular}{|c|c|c|c|c|}
\hline Patient characteristics & ROC & CIS & Test & $p$-value \\
\hline \multicolumn{5}{|l|}{ Age (years): } \\
\hline Range & $20-39$ & $20-40$ & \multirow[t]{2}{*}{$t: 0.229$} & \multirow[t]{2}{*}{0.634} \\
\hline Mean \pm SD & $28.93 \pm 5.94$ & $29.63 \pm 5.37$ & & \\
\hline \multicolumn{5}{|l|}{$B M I\left(\mathrm{~kg} / \mathrm{m}^{2}\right):$} \\
\hline Range & $40-50$ & $40-50$ & \multirow{2}{*}{$t: 0.016$} & \multirow[t]{2}{*}{0.899} \\
\hline Mean \pm SD & $44.67 \pm 3.07$ & $44.57 \pm 3.01$ & & \\
\hline \multicolumn{5}{|l|}{ Sex: } \\
\hline Male $(\%)$ & $11(36.7 \%)$ & $12(40 \%)$ & \multirow[t]{2}{*}{$X^{2}: 0.071$} & \multirow[t]{2}{*}{0.791} \\
\hline Female $(\%)$ & $19(63.3 \%)$ & $18(60 \%)$ & & \\
\hline Surgical characteristics & $\mathrm{ROC}$ & CIS & Test & $p$-value \\
\hline \multicolumn{5}{|l|}{ Duration (minutes): } \\
\hline Range & $45-95$ & $45-95$ & \multirow[t]{2}{*}{$t: 0.002$} & \multirow[t]{2}{*}{0.965} \\
\hline Mean \pm SD & $67.83 \pm 14.95$ & $67.67 \pm 14.25$ & & \\
\hline \multicolumn{5}{|l|}{ Type of surgery: } \\
\hline Laparoscopic cholecystectomy (\%) & $8(26.7 \%)$ & $10(33.3 \%)$ & \multirow[t]{4}{*}{$X^{2}: 0.899$} & \multirow[t]{4}{*}{0.826} \\
\hline Laparoscopic appendicectomy (\%) & $7(23.3 \%)$ & $7(23.3 \%)$ & & \\
\hline Laparoscopic herniorraphy (\%) & $6(20 \%)$ & $7(23.3 \%)$ & & \\
\hline Laparoscopic sleevegastrectomy (\%) & $9(30 \%)$ & $6(20 \%)$ & & \\
\hline Incidence of complication & ROC & CIS & $X^{2}$ & $p$-value \\
\hline Skin Reaction \% & $2(6.7 \%)$ & $1(3.3 \%)$ & 0.351 & 0.554 \\
\hline Bronchospasm \% & $2(6.7 \%)$ & $1(3.3 \%)$ & 0.351 & 0.554 \\
\hline $\mathrm{O}_{2}$ desaturation $\%$ & $1(3.3 \%)$ & $1(3.3 \%)$ & 0.0 & 1.0 \\
\hline
\end{tabular}

$\mathrm{SD}=$ Standard deviation.

Table (2): Timing of intubation in the two studied groups.

\begin{tabular}{lllll}
\hline & ROC & CIS & Test & $p$-value \\
\hline Timing of intubation (seconds): & & & & \\
$\quad$ Range & $60-120$ & $80-120$ & $t: 8.330$ & $0.005^{*}$ \\
Mean \pm SD & $84.0 \pm 18.50$ & $96.0 \pm 13.29$ & & \\
\hline
\end{tabular}

*Denotes significant change.

$\mathrm{SD}=$ Standard deviation .

Table (3): Intubation score in the two studied groups.

\begin{tabular}{lllll}
\hline Intubation & ROC & CIS & Test & $p$-value \\
\hline Score: & & & \\
$\quad$ Excellent (\%) & $15(50 \%)$ & $14(46.7 \%)$ & $\mathrm{X}^{2}: 0.082$ & 0.994 \\
Good (\%) & $10(33.3 \%)$ & $11(36.7 \%)$ & & \\
Poor (\%) & $3(10 \%)$ & $3(10 \%)$ & & \\
$\quad$ Inadequate (\%) & $2(6.7 \%)$ & $2(6.7 \%)$ & & \\
\hline
\end{tabular}




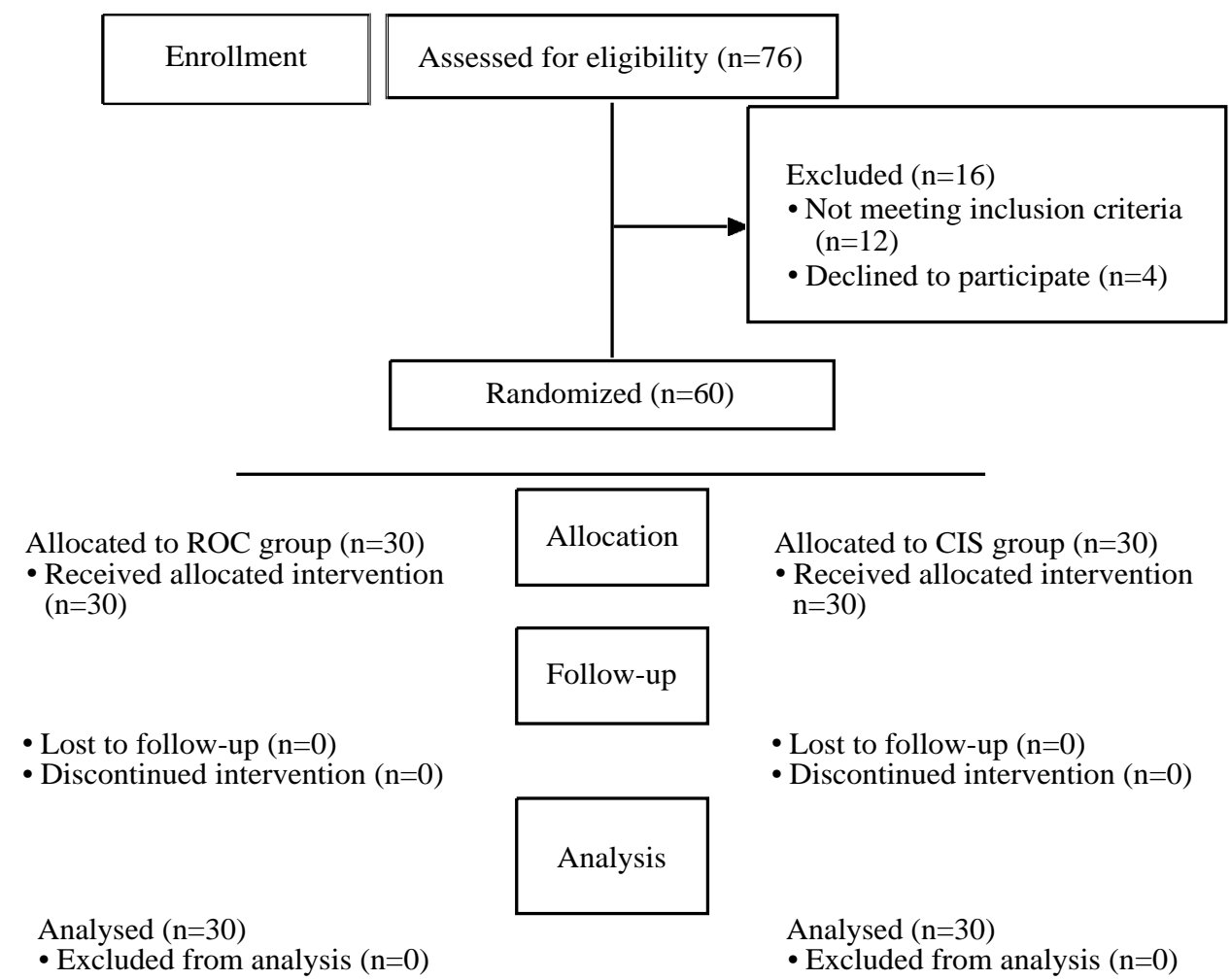

Fig. (1): Consort flowchart of the study.

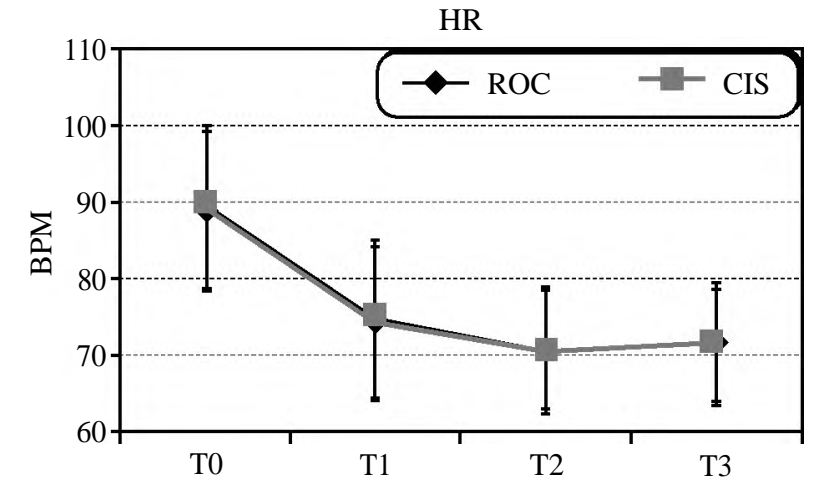

Fig. (2): Comparison of changes in the mean values of HR in the two groups.

\section{Discussion}

The results of this clinical trial showed that the use of rocuronium $(0.9 \mathrm{mg} / \mathrm{kg})$ in rapid sequence induction of anesthesia in morbidly obese patients significantly decreased the onset of relaxation, decreased the timing of intubation, and increased the duration of relaxation than the use of cisatracurium $(0.15 \mathrm{mg} / \mathrm{kg})$. The intubation score, the hemodynamic response, and the incidence of complications were indifferent between the two groups.

The muscle relaxant that may be considered ideal for induction of anesthesia should have short-

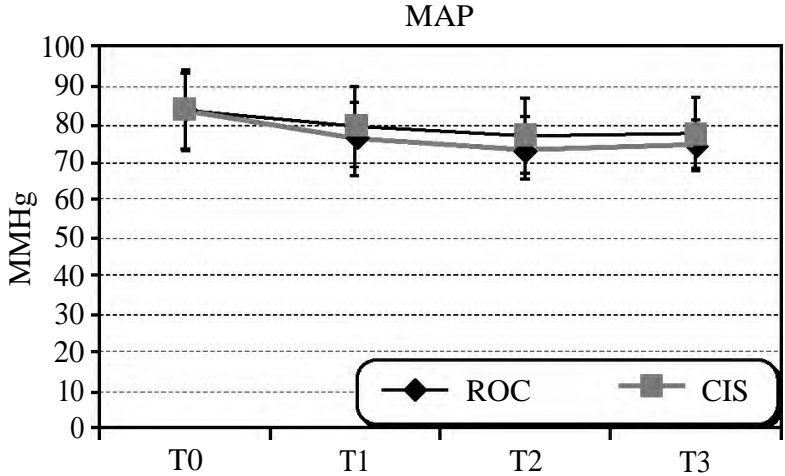

Fig. (3): Comparison of changes in the mean values of MAP in the two studied group.

ened onset and duration of action with optimal intubating conditions [11]. Mount, et al., revealed that rocuronium at a dose of $1 \mathrm{mg} / \mathrm{kg}$ represents an excellent alternative to succinylcholine in rapid sequence induction as it is capable of creating accepted intubating conditions within a short time. However, they advised that rocuronium should be the second option for rapid sequence induction after succinylcholine as it possesses a long duration of action which is feasible only for the prolonged surgeries [12]. With the availability of sugammadex that facilitate rapid reversal of muscle relaxation, rocuronium can be widely used [13] . Heier et al., 
evaluated different doses of rocuronium (up to $2.0 \mathrm{mg} / \mathrm{kg}$ ) to detect a higher probability to obtain rapid and perfect tracheal intubation condition. They revealed that increasing the dose of rocuronium allow rapid and effective condition of tracheal intubation with the disadvantage of increasing the duration of relaxation [14]. On the other hand, Zhou et al revealed a delayed onset of action of rocuronium when used in a dose of $0.6 \mathrm{mg} / \mathrm{g}$ in comparison to rapacuruim $1.5 \mathrm{mg} / \mathrm{kg}$ [15]

The clinical study of Levy et al purposed to evaluate the hemodynamic response and the histamine release with the use of increased the dose of rocuronium (2, 3, and 4 times the EF 95) when used with nitrous-sufentanil anesthesia. It found that the dose of rocuronium can be increased up to 4 folds with minimal effect on hemodynamic parameters and histamine release [16]. In addition, Pino et al suggested that the use of rocuronium at a dose of 0.9 to $1.2 \mathrm{mg} / \mathrm{kg}$ led to a faster onset of action and better intubating condition as compared to mivacurium $0.25 \mathrm{mg} / \mathrm{kg}$. Rocuronium had the disadvantage of significant prolongation of the duration of action if it was used in larger doses [17] Moreover, McCourt et al compared the use of two different doses of rocuronium in rapid sequence induction with $(0.6$ or $1.0 \mathrm{mg} / \mathrm{kg})$ with the use of succinylcholine and concluded that rocuronium at a dose of $1.0 \mathrm{mg} / \mathrm{kg}$ represents a good alternative to succinylcholine in rapid sequence induction of anesthesia [18]

Although cisatracurium possesses many advantages over other neuromuscular blocking agents especially the intermediate duration of action, it is thought that it has a relatively longer onset of action when used in the equipotent doses [19] Bluestein et al., revealed that increasing the dose of cisatracurium from $0.1 \mathrm{mg} / \mathrm{kg}$ to 0.15 or $0.2 \mathrm{mg} / \mathrm{kg}$ is capable of shortening the mean onset of its action and increasing its duration [20]. Moreover, Mandel, et al conducted a study to detect the mean effective dose of cisatracurium that enables adequate intubation within less than 90 seconds. They conclude that the use of a dose of $0.15 \mathrm{mg} / \mathrm{kg}$ can produce suitable intubation conditions within 90-120 seconds and the use of a dose of $0.2 \mathrm{mg} / \mathrm{kg}$ can create the suitable intubating conditions within less than 90 seconds [21].

The study of Lee et al., examined the effect of the use of either rocuronium or cisatracurium on the intubating condition of remifentanil-propofol rapid sequence induction and suggested that cisatracurium can provide good conditions of intubation as that obtained by the equipotent dose of rocuronium [10]. Also, El-Kasaby et al., found that atra- curium is a more effective neuromuscular blocking agent than cisatracurium when they used in double of their ED 95. However, increasing the dose of cisatracurium to be $4 \times$ ED 95 or $6 x E D 95$ provide more rapid and more efficient relaxation with stable hemodynamic parameters and decreased histamine release clinically [22].

Doenicke et al., studied the onset and the quality of intubation with the use of higher doses of cisatracurium $(0.25$ or $0.15 \mathrm{mg} / \mathrm{kg})$ or vecuronium $(0.15 \mathrm{mg} / \mathrm{kg})$ and found that increasing the dose of cisatracurium up to $0.25 \mathrm{mg} / \mathrm{kg}$ can allow intubation within 60 seconds without significant clinical effect on the histamine release [23]

The evaluation of a single dose only of rocuronium or cisatracurium limited this clinical trial as different dose regimens were not evaluated. Moreover, the lack of comparison of either rocuronium or cisatracurium to the suxamethonium added to the study limitations.

We can conclude that the use of the triple the $95 \%$ of the mean effective dose of rocuronium $(0.9 \mathrm{mg} / \mathrm{kg})$ in rapid sequence induction of anesthesia fastened the onset of relaxation and the time of intubation than the equipotent dose of cisatracurium $(0.15 \mathrm{mg} / \mathrm{kg})$ with comparable intubation score, effect on the hemodynamic parameters, and the incidence of complication. Rocuronium increased the duration of relaxation more than cisatracurium.

\section{Acknowledgments:}

We would express our great thanks to our colleges in the department of Anesthesia and Surgical Intensive Care, Faculty of Medicine, Tanta University, Egypt.

\section{Conflict of interest statement: \\ No conflict of interest.}

\section{References}

1- NG M., FLEMING T., ROBINSON M., THOMSON B., et al.: Global, regional, and national prevalence of overweight and obesity in children and adults during 19802013: A systematic analysis for the Global Burden of Disease Study 2013. The lancet., 384 (9945): 766-81, 2014.

2- COOPER R., MIRAKHUR R. and MADDINENI V.: Neuromuscular effects of rocuronium bromide (Org 9426) during fentanyl and halothane anaesthesia. Anaesthesia., 48 (2): 103-5, 1993.

3- COOPER R., MIRAKHUR R., CLARKE R. and BOULES $\mathrm{Z}$.: Comparison of intubating conditions after administration of Org 9426 (rocuronium) and suxamethonium. Br. J. Anaesth., 69 (3): 269-73, 1992. 
4- SØRENSEN M., BRETLAU C., GÄTKE M., SØRENSEN A. and RASMUSSEN L.: Rapid sequence induction and intubation with rocuronium-sugammadex compared with succinylcholine: A randomized trial. Br. J. Anaesth., 108 (4): 682-9, 2012.

5- HUNTER J.: Rocuronium: The newest aminosteroid neuromuscular blocking drug. Elsevier, 1996.

6- KOPMAN A., CHIN W. and MOE J.: Dose-response relationship of rocuronium: A comparison of electromyographic vs. acceleromyographic-derived values. Acta. Anaesthesiol. Scand., 49 (3): 323-7, 2005.

7- CARROLL M., MIRAKHUR R., LOWRY D., McCOURT K. and KERR C.: Neuromuscular blocking effects and train of four fade with cisatracurium: Comparison with other nondepolarising relaxants. Anaesthesia., 53 (12): 1169-73, 1998

8- LEYKIN Y., PELLIS T., DEL MESTRO E., MARZANO B., FANTI G. and BRODSKY J.B.: Anesthetic management of morbidly obese and super-morbidly obese patients undergoing bariatric operations: Hospital course and outcomes. Obes. Surg., 16 (12): 1563-9, 2006.

9- SCHELLER M.S., ZORNOW M.H. and SAIDMAN L.J.: Tracheal intubation without the use of muscle relaxants: A technique using propofol and varying doses of alfentanil. Anesth. Analg., 75 (5): 788-93, 1992.

10- LEE H., JEONG S., CHOI C., JEONG H., LEE S. and JEONG S.: Anesthesiologist's satisfaction using between cisatracurium and rocuronium for the intubation in the anesthesia induced by remifentanil and propofol. Korean J. Anesthesiol., 64 (1): 34-9, 2013.

11- SLUGA M., UMMENHOFER W., STUDER W., SIEGEMUND M. and MARSCH S.C.: Rocuronium versus succinylcholine for rapid sequence induction of anesthesia and endotracheal intubation: A prospective, randomized trial in emergent cases. Anesth. Analg., 101 (5): 135661, 2005.

12- TRAN D.T., NEWTON E.K., MOUNT V.A., LEE J.S., WELLS G.A. and PERRY J.J.: Rocuronium versus succinylcholine for rapid sequence induction intubation. Cochrane Database of Systematic Reviews, (10), 2015.

13- SOTO R., JAHR J.S., PAVLIN J., et al.: Safety and Efficacy of Rocuronium With Sugammadex Reversal Versus Succinylcholine in Outpatient Surgery-A Multicenter, Randomized, Safety Assessor-Blinded Trial. Am. J. Ther., 23 (6): e1654-e62, 2016.
14- HEIER T. and CALDWELL J.E.: Rapid tracheal intubation with large-dose rocuronium: A probability-based approach. Anesth. Analg., 90 (1): 175-9, 2000.

15- ZHOU T., WHITE P., CHIU J., et al.: Onset/offset characteristics and intubating conditions of rapacuronium: A comparison with rocuronium. Br. J. Anaesth., 85 (2): 246$50,2000$.

16- LEVY J.H., DAVIS G.K., DUGGAN J. and SZLAM F. Determination of the hemodynamics and histamine release of rocuronium (Org 9426) when administered in increased doses under N2O/O2-sufentanil anesthesia. Anesth. Analg., 78 (2): 318-21, 1994

17- PINO R.M., ALI H.H., DENMAN W.T., BARRETT P.S and SCHWARTZ A.: A comparison of the intubation conditions between mivacurium and rocuronium during balanced anesthesia. Anesthesiology: The Journal of the American Society of Anesthesiologists., 88 (3): 673-8, 1998.

18- McCOURT K., SALMELA L., MIRAKHUR R., et al.: Comparison of rocuronium and suxamethonium for use during rapid sequence induction of anaesthesia. Anaesthesia., 53 (9): 867-71, 1998.

19- WASTILA W.B., MAEHR R.B., TURNER G.L., HILL D.A., PHIL M. and SAVARESE J.J.: Comparative pharmacology of cisatracurium (51 W89), atracurium, and five isomers in cats. Anesthesiology: The Journal of the American Society of Anesthesiologists., 85 (1): 169-77, 1996

20- BLUESTEIN L.S., STINSON L.W., LENNON R.L., QUESSY S.N. and WILSON R.M.: Evaluation of cisatracurium, a new neuromuscular blocking agent, for tracheal intubation. Can. J. Anaesth., 43 (9): 925-31, 1996.

21- MANDAL P.: Intubating conditions after cisatracurium administration: A dose response study in adults. J. Anaesth. Clin. Pharmacol., 18: 147-51, 2002.

22- EL-KASABY A., ATEF H., HELMY A. and EL-NASR M.A.: Cisatracurium in different doses versus atracurium during general anesthesia for abdominal surgery. Saudi journal of anaesthesia., 4 (3): 152, 2010.

23- DOENICKE A.W., CZESLICK E., MOSS J. and HOERNECKE R.: Onset time, endotracheal intubating conditions, and plasma histamine after cisatracurium and vecuronium administration. Anesth. Analg., 87 (2): 434-8, 1998. 


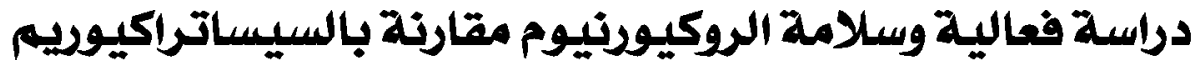

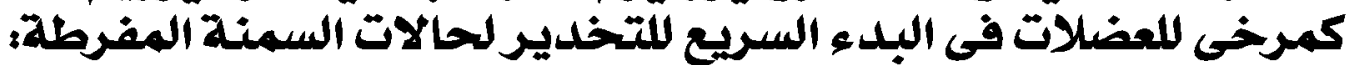 دراسة مقارنة عشوائية التهدية}

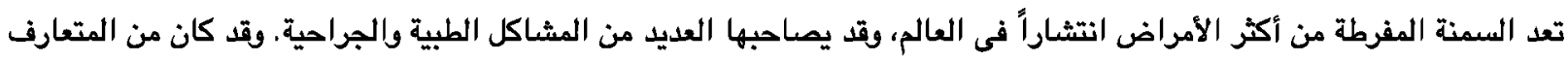

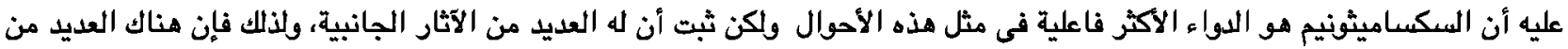

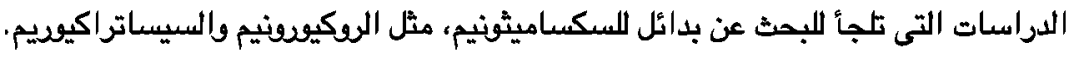

الهدف من الدراسة هو المقارثة بين الروكيورنيم والسياتراكيوريم كمرخي للعضلات في البدء السريع للتخدير في حالات السمنة المفرطة.

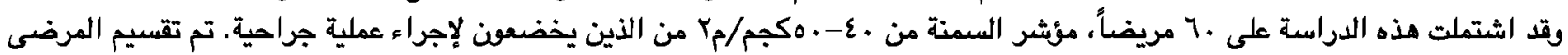

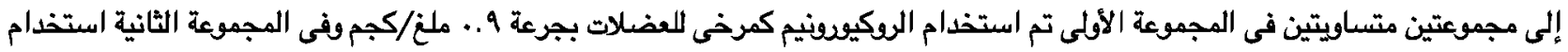

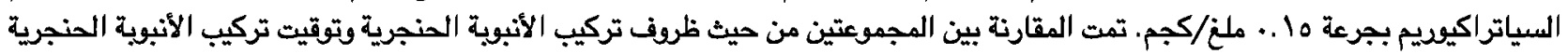

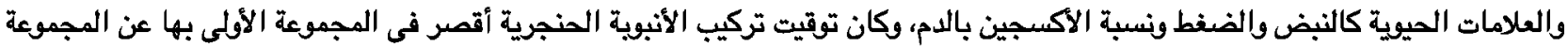

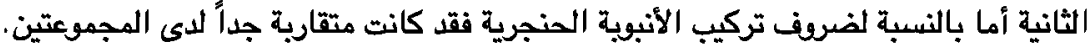

نستنتج من هذه الدراسة أن عقار الركيورنيم يتيح لنا الفرصة لتركيب الأنبوبة الحنجرية في فترة زمنية أقصر من السيساتراكيويم لكن كلاهما يعطينا ظروف متقاربة لتركيب الأنبوبة الصنجرية. 